\title{
Evaluation of the New Version of the Laser-Optical Disdrometer, OTT Parsivel ${ }^{2}$
}

\author{
Ali TOKAY \\ Joint Center for Earth Systems Technology, University of Maryland, Baltimore County, Baltimore, \\ and NASA Goddard Space Flight Center, Greenbelt, Maryland \\ David B. WolfF And Walter A. Petersen \\ NASA Wallops Flight Facility, Wallops Island, Virginia
}

(Manuscript received 12 August 2013, in final form 23 January 2014)

\begin{abstract}
A comparative study of raindrop size distribution measurements has been conducted at NASA's Goddard Space Flight Center where the focus was to evaluate the performance of the upgraded laser-optical OTT Particle Size Velocity (Parsivel ${ }^{2}$; P2) disdrometer. The experimental setup included a collocated pair of tipping-bucket rain gauges, OTT Parsivel (P1) and P2 disdrometers, and Joss-Waldvogel (JW) disdrometers. Excellent agreement between the two collocated rain gauges enabled their use as a relative reference for event rain totals. A comparison of event total showed that the $\mathrm{P} 2 \mathrm{had}$ a $6 \%$ absolute bias with respect to the reference gauges, considerably lower than the P1 and JW disdrometers. Good agreement was also evident between the JW and P2 in hourly raindrop spectra for drop diameters between 0.5 and $4 \mathrm{~mm}$. The P2 drop concentrations mostly increased toward small sizes, and the peak concentrations were mostly observed in the first three measurable size bins. The P1, on the other hand, underestimated small drops and overestimated the large drops, particularly in heavy rain rates. From the analysis performed, it appears that the P2 is an improvement over the P1 model for both drop size and rainfall measurements. P2 mean fall velocities follow accepted terminal fall speed relationships at drop sizes less than $1 \mathrm{~mm}$. As a caveat, the $\mathrm{P} 2$ had approximately $1 \mathrm{~m} \mathrm{~s}^{-1}$ slower mean fall speed with respect to the terminal fall speed near $1 \mathrm{~mm}$, and the difference between the mean measured and terminal fall speeds reduced with increasing drop size. This caveat was recognized as a software bug by the manufacturer and is currently being investigated.
\end{abstract}

\section{Introduction}

The Particle Size Velocity (Parsivel) is a laser-optical disdrometer that measures the size and fall velocity of hydrometeors. Löffler-Mang and Joss (2000, hereafter LJ00), who introduced the specifications and measurement principles of the Parsivel, described three major advantages with respect to commercially available disdrometers at that time. First, they pointed out the easyto-operate, robust, and low-cost features of the Parsivel. Second, they mentioned that the Parsivel could estimate the size of drizzle drops down to a 0.1-mm diameter with modifications made to the optical system. Third, they stated that the Parsivel estimates the size and fall velocity of snowflakes and is useful for discriminating the

Corresponding author address: Ali Tokay, NASA Goddard Space Flight Center, Code 612.0, Greenbelt, MD 20771.

E-mail: ali.tokay-1@nasa.gov hydrometeor type, which makes the Parsivel a present weather sensor.

LJ00 evaluated the performance of the Parsivel through comparison with a collocated impact-type Joss-Waldvogel (JW) disdrometer (Joss and Waldvogel 1967) and a recording Hellmann accumulation gauge (Sevruk 1996) in rain. They found reasonable agreement between the JW and Parsivel raindrop size distribution (DSD) in the 0.7-2-mm drop-diameter range, while the Parsivel detected higher concentrations at sizes less $0.7 \mathrm{~mm}$, and a limited sample was the cause for the noticeable differences for drops larger than $2 \mathrm{~mm}$ in diameter. Reasonable agreement was also noted between the JW and Parsivel rain-rate time series as well as between Parsivel and the Hellmann gauge for the daily rain totals.

The Parsivel disdrometer became commercially available through PM Tech Inc., and Yuter et al. (2006) operated a loan unit in a rain/wet snow event and in a dry snow event in the Cascade and Rocky Mountains, 
respectively. They found that the hydrometeor fall velocities were noticeably different at different temperature ranges as the phase of hydrometeors change. The size distributions were also noticeably different during different storm phases as classified by environmental temperature.

Two PM Tech Parsivel units were operated at National Aeronautics and Space Administration (NASA)'s Wallops Flight Facility (WFF) for several years, where both units recorded $12 \%$ and $19 \%$ less rainfall than collocated rain gauges in 30 rain events. These two units also participated in the Canadian CloudSat/CloudAerosol Lidar and Infrared Pathfinder Satellite Observations (CALIPSO) Validation Project (C3VP). Battaglia et al. (2010) used data from C3VP to evaluate the performance of the PM Tech Parsivel in snow relative to a collocated two-dimensional video disdrometer (2DVD). They found significant differences in snowflake size distribution and fall velocities between the two instruments and focused on the shortcoming of Parsivel measurements.

Krajewski et al. (2006) compared a PM Tech Parsivel with a dual-beam spectropluviometer (DBS) (Hauser et al. 1984) and a 2DVD (Kruger and Krajewski 2002; Schönhuber et al. 2007) in rain. Agreement between the DSD of the three disdrometers was observed for drop diameters ranging from 0.5 to $4 \mathrm{~mm}$, while the Parsivel had lower drop concentrations at sizes less than $0.5 \mathrm{~mm}$ in five major events. The mean Parsivel fall velocity was higher than terminal fall speeds for raindrops (Beard 1976) at sizes less than $1 \mathrm{~mm}$ in diameter, and the reverse was true at sizes above $1.4 \mathrm{~mm}$. Krajewski et al. (2006) reported that the Parsivel estimated higher rain accumulations than both of the other collocated disdrometers as well as nearby tipping-bucket rain gauges in each of the five major events, but the differences were $16 \%$ or less with respect to the rain gauges.

In 2005, OTT Hydromet purchased all the rights of the Parsivel and redesigned the instrument to specifically target applications in the transportation sector. Indeed, transportation agencies around the world purchased the OTT Parsivels (P1) to be used as a present weather sensor. There are several differences between the OTT and PM Tech models. The output voltages in the PM Tech and OTT Parsivels were sampled at 10 and $50 \mathrm{kHz}$, respectively (Battaglia et al. 2010). One sample is therefore taken every 0.1 and $0.02 \mathrm{~ms}$ in the PM Tech and OTT Parsivels, respectively. The P1 used a much less expensive laser device and reduced homogeneity across the laser beam resulted in an overestimation of large drops relative to a collocated 2DVD in northern Alabama (Tokay et al. 2013, hereafter TPGW13). The event rain totals from P1 were nearly $14 \%$ higher than estimates from collocated tipping-bucket gauges. The P1 was calibrated using a rotating precision disk, and the mean fall velocities at sizes above $1.4 \mathrm{~mm}$ in diameter were lower but much closer to the terminal fall speed than the PM Tech Parsivel.

The P1 participated in the first field experiment for intercomparison of rain intensity measurements; the field experiment was organized by the World Meteorological Organization in central Italy, where 30 selected rain gauges and optical disdrometers operated for 1.5 years (Vuerich et al. 2009). The $\mathrm{P} 1$ rated a score of 3 out 5 for 1-min rain rate with respect to selected reference gauges. Lanza and Vuerich (2009) pointed out that optical disdrometers overestimated rain intensity and the overestimation increased with increasing rain rate. This finding is consistent with the study by Thurai et al. (2011) and TPGW13.

In 2011, OTT introduced a new model of the Parsivel, namely, Parsivel ${ }^{2}$ (P2). A beta version of P2 was evaluated through a comparative study at NASA's Goddard Space Flight Center. This study presents the performance of P2 with respect to the P1 model through an experimental study in rain. The experimental study also includes a JW disdrometer and two tipping-bucket rain gauges. It should be noted that none of the disdrometers used in this study is considered as an absolute reference. The technical details of the Parsivel disdrometer are given in section 2, which is followed by the rainfall statistics and the measurement site and data in sections 3 and 4, respectively. The comparison of event rainfall totals between the disdrometers and rain gauges is also given in section 4 . The comparison of hourly DSD between the old and new models of the OTT Parsivel and collocated JW is presented in section 5, while section 6 provides the comparison of fall velocity measurements between the old and new OTT Parsivel. The probability of and cumulative distributions of fitted gamma parameters and integral rain parameters are presented in section 7 followed by conclusions in the last section.

\section{Parsivel disdrometer}

All the Parsivel models measure the size and fall velocity of hydrometeors that fall through a laser sheet independently. The laser sheet is approximately $180 \mathrm{~mm}$ long, $30 \mathrm{~mm}$ wide, and $1 \mathrm{~mm}$ high. The size of the hydrometeor is estimated from the maximum attenuation of the signal. The duration of the hydrometeor within the laser beam provides the fall speed. The raindrops falling through the laser sheet are assumed to be spherical for sizes less than $1 \mathrm{~mm}$ in diameter, while the drop axis ratio varies linearly from 1 to 0.7 for drops between 1 and $5 \mathrm{~mm}$. For drops larger than $5 \mathrm{~mm}$, the axis ratio is set to 
0.7. The Parsivel processing software assumes snowflakes as spheres and therefore the measured "Parsivel size" is a one-dimensional length, which is not necessarily representative of the equivalent diameter.

The Parsivel's nominal sampling area is $54 \mathrm{~cm}^{2}$, but the effective sampling area is calculated considering the partially observed hydrometeors. While the sampling area was intentionally designed to reduce the probability of multiple hydrometeors being detected at the same time, this may not be avoidable, particularly in the presence of abundant small hydrometeors. Also, secondary particles may result from splashes, and windy conditions can result in the particles falling through the laser sheet at an angle. For analysis of raindrops herein, we eliminated the suspect false particles whose fall speeds fell outside the $\pm 50 \%$ of the generally accepted range of drop terminal fall speed; however, this subjective criterion eliminates mainly the small drops. The terminal fall speed table that is used in this study is based on wind tunnel experiments following Beard (1976).

The Parsivel's raw output provides the number of drops in a $32 \times 32$ size versus fall velocity matrix. The size range is from 0 to $25 \mathrm{~mm}$, and the class width increases with the size from 0.125 to $3 \mathrm{~mm}$. The first two size classes are left empty due to the low signal-to-noise ratio, and the minimum detectable size is approximately $0.25 \mathrm{~mm}$. The fall velocity range is from 0 to $20 \mathrm{~m} \mathrm{~s}^{-1}$ and the class width increases with fall velocity. Thus, the Parsivel cannot provide precise size and fall velocity of the hydrometeors, particularly at larger sizes and faster fall speeds. The calculated DSD parameters and maximum size, therefore, are subject to quantization errors.

Homogeneity of the laser sheet is crucial for accuracy of the Parsivel measurements. LJ00 conducted a laboratory study to test the accuracy of size and fall velocity of PM Tech Parsivel measurements. They showed that the overall error in estimating the drop diameter does not exceed $\pm 0.1 \mathrm{~mm}$ plus $\pm 5 \%$, and the errors in fall velocity are within $25 \%$ for 0.3 -mm-diameter drops and $10 \%$ for 5 -mm-diameter drops. High-precision reference particles at $0.5,1,2$, and $4 \mathrm{~mm}$ are employed to calibrate $\mathrm{P} 1$ with a rotating disk. The manufacturer reports that the accuracy of rain rate is $\pm 5 \%$, while the radar reflectivity accuracy is $\pm 20 \%$. A key issue with P1 was the inhomogeneous laser beam. It was pointed out that large particles could be overestimated by $20 \%$, depending on the precipitation intensity (K. Nemeth, OTT, 2008, personal communication). Indeed, Thurai et al. (2011) showed higher median mass diameters ( $D_{\text {mass }}$ ) estimated by the P1 than the 2DVD at $D_{\text {mass }}>$ $2 \mathrm{~mm}$, and when the rain intensity was greater than $20 \mathrm{~mm} \mathrm{~h}^{-1}$. TPGW13 also showed that higher raindrop concentrations were detected by the $\mathrm{P} 1$ compared to the JW and the 2DVD. The P1 raindrop fall velocities, on the other hand, agreed better with the terminal fall speed of raindrops, particularly for midsize drops (1$3 \mathrm{~mm}$ ) than those from PM Tech (TPGW13). The sampling output rate is user selectable but can be as high as $10 \mathrm{~s}$ as opposed to 1-min output sampling for the PM Tech Parsivel.

$\mathrm{P} 2$ is a new design where the electronics are placed in the sleeve rather than in the sensor's two heads as with the P1. The sensor head is also heavier than the previous model's. The manufacturer suggests that the key improvement is the use of a more expensive laser device and better homogeneity of the laser sheet. The measurement accuracy was reported to \pm 1 size class in $\mathrm{P} 2$ as opposed to \pm 3 class in P1 up to $2 \mathrm{~mm}$, while for the particles above $2 \mathrm{~mm}$, the accuracy is \pm 0.5 size class in $\mathrm{P} 2$ as opposed to \pm 2 in P1. It should be noted that the class width doubles at $2.8 \mathrm{~mm}$.

\section{Rainfall statistics}

Percent bias and percent absolute bias are used to compare the event rain totals between the disdrometer and rain gauges, and raindrop size distribution and integral rainfall parameters between the disdrometers. The percent bias and absolute percent bias between the measurements of the two instruments $(x, y)$ for $n$ samples are calculated as

$$
\begin{gathered}
\text { percent_bias }=\frac{\text { bias }}{\langle x, y\rangle}, \\
\text { percent_absolute_bias }=\frac{\text { absolute_bias }}{\langle x, y\rangle},
\end{gathered}
$$

where

$$
\begin{aligned}
\text { bias } & =\frac{1}{n} \sum_{i=1}^{n}\left(x_{i}-y_{i}\right), \\
\text { absolute_bias } & =\frac{1}{n} \sum_{i=1}^{n}\left|x_{i}-y_{i}\right|, \quad \text { and } \\
\langle x, y\rangle & =\frac{1}{n} \sum_{i=1}^{n} \frac{\left(x_{i}+y_{i}\right)}{2} .
\end{aligned}
$$

If one of the variables is from a reference instrument (e.g., $x$ ), then the denominator in Eqs. (1) and (2) is expressed as

$$
\langle x\rangle=\frac{1}{n} \sum_{i=1}^{n} x_{i}
$$




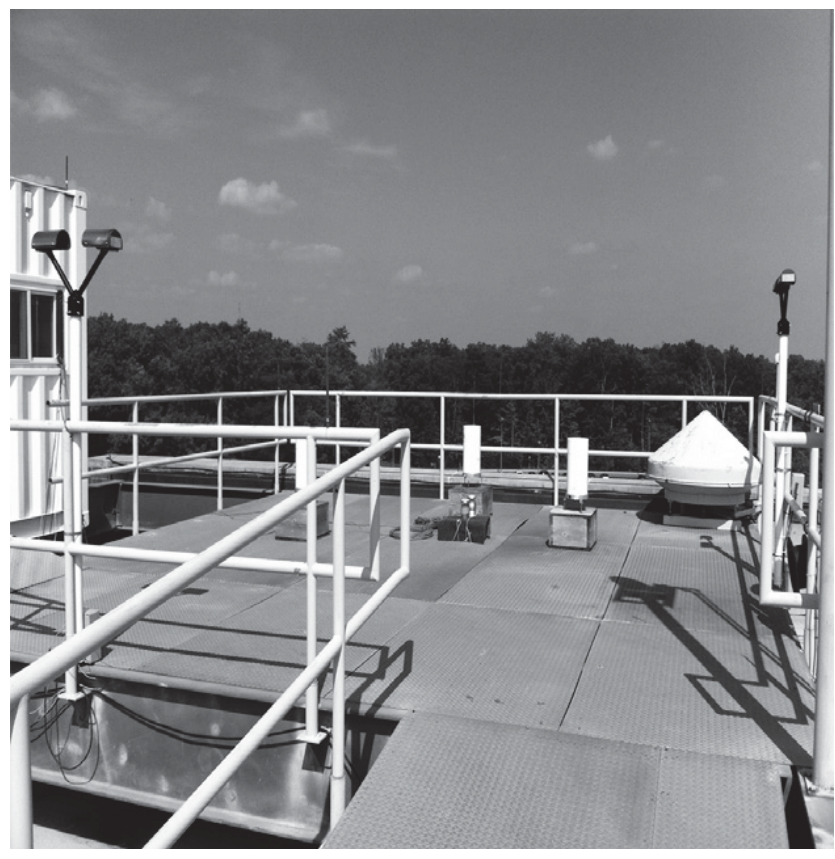

FIG. 1. In situ precipitation measuring test site at the roof of building 33 at NASA's Goddard Space Flight Center, Greenbelt, MD. OTT Parsivel and Parsivel ${ }^{2}$ are on the post at the left and right sides, respectively. The impact-type JW disdrometer is in the middle sitting on a cinder block with green water-absorbing material. Two tipping-bucket rain gauges are in the middle behind the JW disdrometer sitting on a wooden box. A third tipping-bucket gauge was also in the field (left) but did not operate for the experiment period.

In this study, the gauge that was operated for all rain events is considered as a reference. The tipping-bucket rain gauges are manufactured by Met One Inc. (model 370) and were previously tested through comparative field studies with Texas Electronics (model TR-525I) rain gauges in northern Alabama (TPGW13), and with Hydrological Services (model TB3) syphon rain gauges at NASA WFF, Wallops Island, Virginia.

\section{Measurement site and data}

During tests of the P2, the P2, P1, JW, and two Met One Inc. tipping-bucket rain gauges were collocated on the roof of building 33 at NASA's Goddard Space Flight Center $\left(39.00^{\circ} \mathrm{N}, 76.87^{\circ} \mathrm{W}\right)$ (Fig. 1). The time of each tip (0.254-mm accumulation) was recorded for the gauges, while drop counts detected by all three disdrometers were first recorded at 10-s intervals and then integrated to 1-min values. The impact-type JW disdrometer determines the raindrop size by assuming that the raindrops are falling at their respective terminal fall speeds and provides the drop counts in both 127 and 20 unequal size classes. We used the former to calculate the integral rain parameters and the latter to compare the composite
DSD with the Parsivel disdrometers. The details of JW disdrometers can be found in Tokay et al. (2005) and the references therein.

During the experiment period (28 February-2 August 2011), there were 36 rain events where the rain totals exceeded 1-mm rainfall. Here, we define a rain event as a rain period separated by 2 -h or longer rain-free periods in the rain-rate time series of the JW disdrometer, and a rain/no-rain threshold was set at a minimum of 10 drops and a rain rate of $0.1 \mathrm{~mm} \mathrm{~h}^{-1}$ for all three disdrometers. For total rainfall, the reference rain gauge recorded $381 \mathrm{~mm}$ of rainfall. The second gauge failed to operate in four events; nonetheless, it recorded just $2 \%$ less rainfall than the reference gauge when the total rainfall was recalculated from the remaining rain events. In comparisons to the gauges, the P2 recorded $349 \mathrm{~mm}$ of rainfall in 145 rainy hours, while P1 and JW had $404 \mathrm{~mm}$ in 134 rainy hours and $325 \mathrm{~mm}$ in $166 \mathrm{~h}$, respectively.

Considering event rain totals, excellent agreement was found between the two rain gauges, where percent bias and percent absolute bias were $-2 \%$ and $4 \%$, respectively, in 32 events (Fig. 2a). The JW disdrometer recorded higher event rain totals than the rain gauge when the event total was less than $4 \mathrm{~mm}$ and the converse was true at higher event totals (Fig. 2b). The absolute bias was $15 \%$, higher than a similar study in northern Alabama (TPGW13), but it was within the manufacturer-specified limits (Tokay et al. 2005). The P1 overestimated half of the rain events with respect to the gauge and the percent absolute bias was $18 \%$, higher than the TPGW13 study (Fig. 2c). The P2 had the best agreement with the rain gauge in event rain totals, where the absolute bias was $6 \%$ (Fig. 2d). The differences in rainfall characteristics and environmental conditions resulted in differences in rainfall statistics between this and the TPGW13 study. It seems possible that wind and turbulent conditions on the roof could have contributed to higher differences in event totals between the instruments. Unfortunately, there was no recording wind sensor available. However, wind measurements from a nearby station are provided for the comparison of the DSD measurements in the next section.

The Parsivel and JW disdrometers have nearly the same sampling area and we used the same rain/no-rain criteria, so the comparison of rainy minutes between the disdrometers provides information on the sensitivity of each disdrometer to rain. The JW disdrometer recorded more rainy minutes than both Parsivels in every rain event, and the percent absolute bias was $20 \%$ and $12 \%$ between JW and P1 and between JW and P2, respectively (Figs. 3a,b). The $\mathrm{P} 2$ recorded more rainy minutes than P1, where the absolute bias was $8 \%$ (Fig. 3c). This 

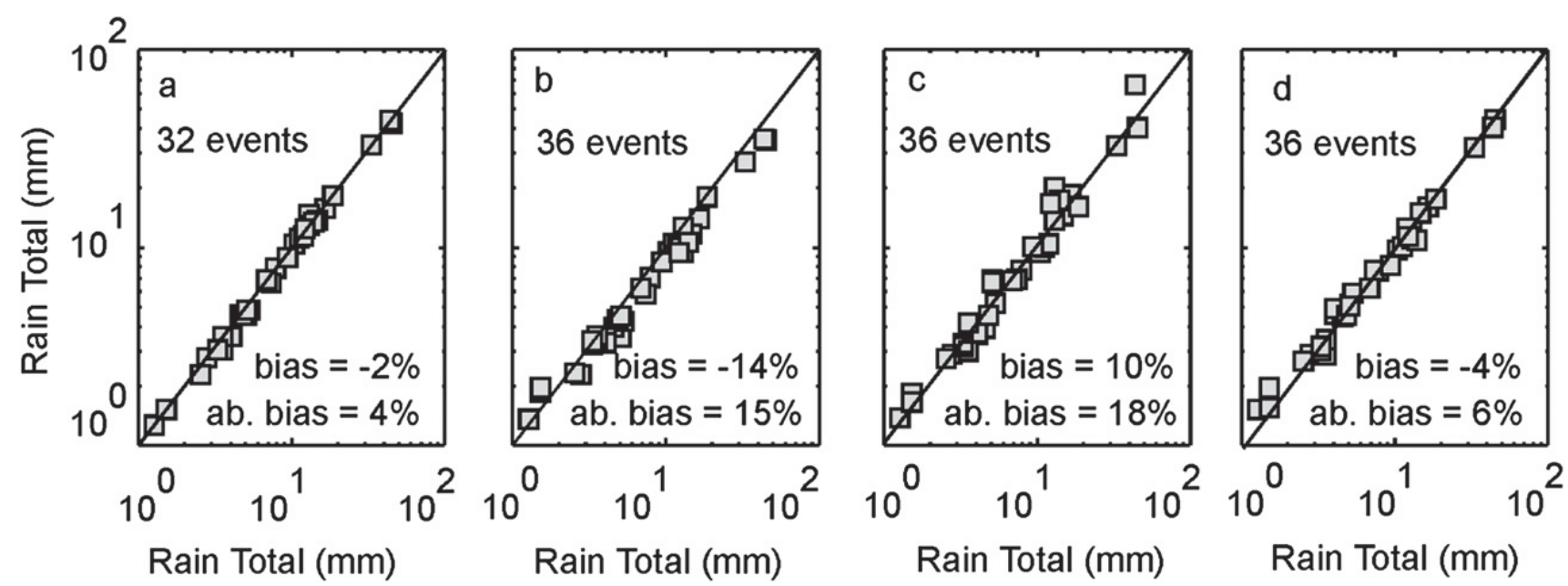

FIG. 2. Comparison of event rain totals (a) between the two MetOne Inc. tipping-bucket rain gauge, and (b) between the reference gauge and JW, (c) between the reference gauge and the OTT Parsivel, and (d) between the reference gauge and OTT Parsivel ${ }^{2}$ disdrometers. The percent bias and absolute bias are also given.

demonstrates that $\mathrm{P} 2$ is more sensitive than $\mathrm{P} 1$ but not as sensitive as the JW disdrometer for detecting rainfall.

\section{Raindrop size distribution measurements}

Midsize (1-3 mm) drops are the main contributor to rainfall, while large drops (greater than $3 \mathrm{~mm}$ ) contribute significantly in heavy rain. The agreement between the disdrometer DSDs at these size ranges is directly linked to the differences in event rain totals discussed previously. The DSD is expressed as the number of drops per volume of air for a given drop size interval.
Considering the Parsivel disdrometer, the raw output is the number of drops at the $i$ th size and $j$ th velocity bin $\left(C_{i, j}\right)$ and DSD is calculated as

$$
N(D)=\frac{1}{\text { Time }} \sum_{i=1}^{n} \sum_{j=1}^{m} \frac{C_{i, j}}{v_{j} \operatorname{Area}\left(D_{i}\right) \Delta D_{i}}
$$

where $\Delta D_{i}$ is the width of the $i$ th size bin; and $n$ and $m$ are the number of size and velocity bins, respectively, and both are equal to 32 . Area $\left(D_{i}\right)$, the effective disdrometer sampling area, is calculated considering partially detected drops across Parsivels' laser sheet and is
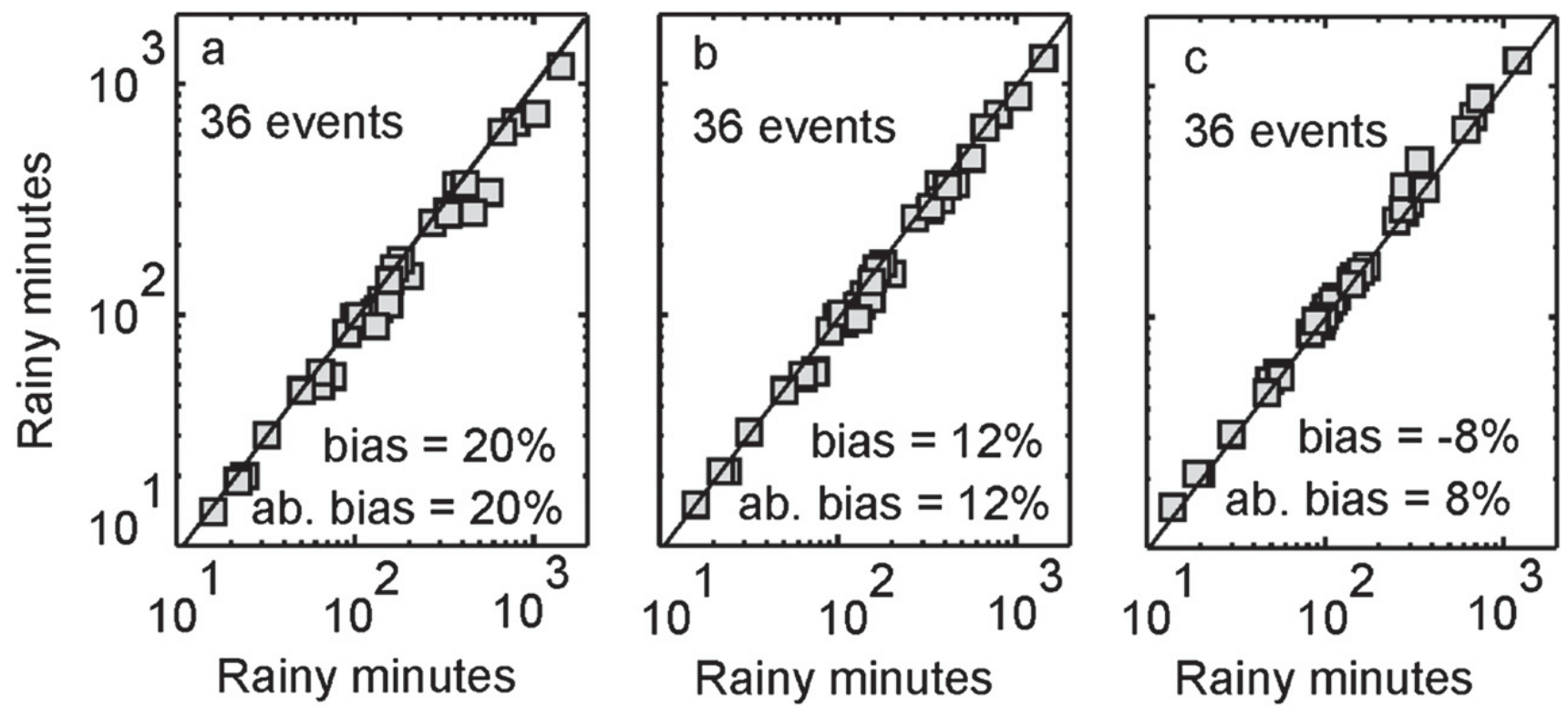

FIG. 3. Comparison of event rainy minutes (a) between the JW and OTT Parsivel disdrometers, (b) between the JW and OTT Parsivel ${ }^{2}$ disdrometers, and (c) between the OTT Parsivel and OTT Parsivel ${ }^{2}$ disdrometers. The bias and absolute bias are also given. 

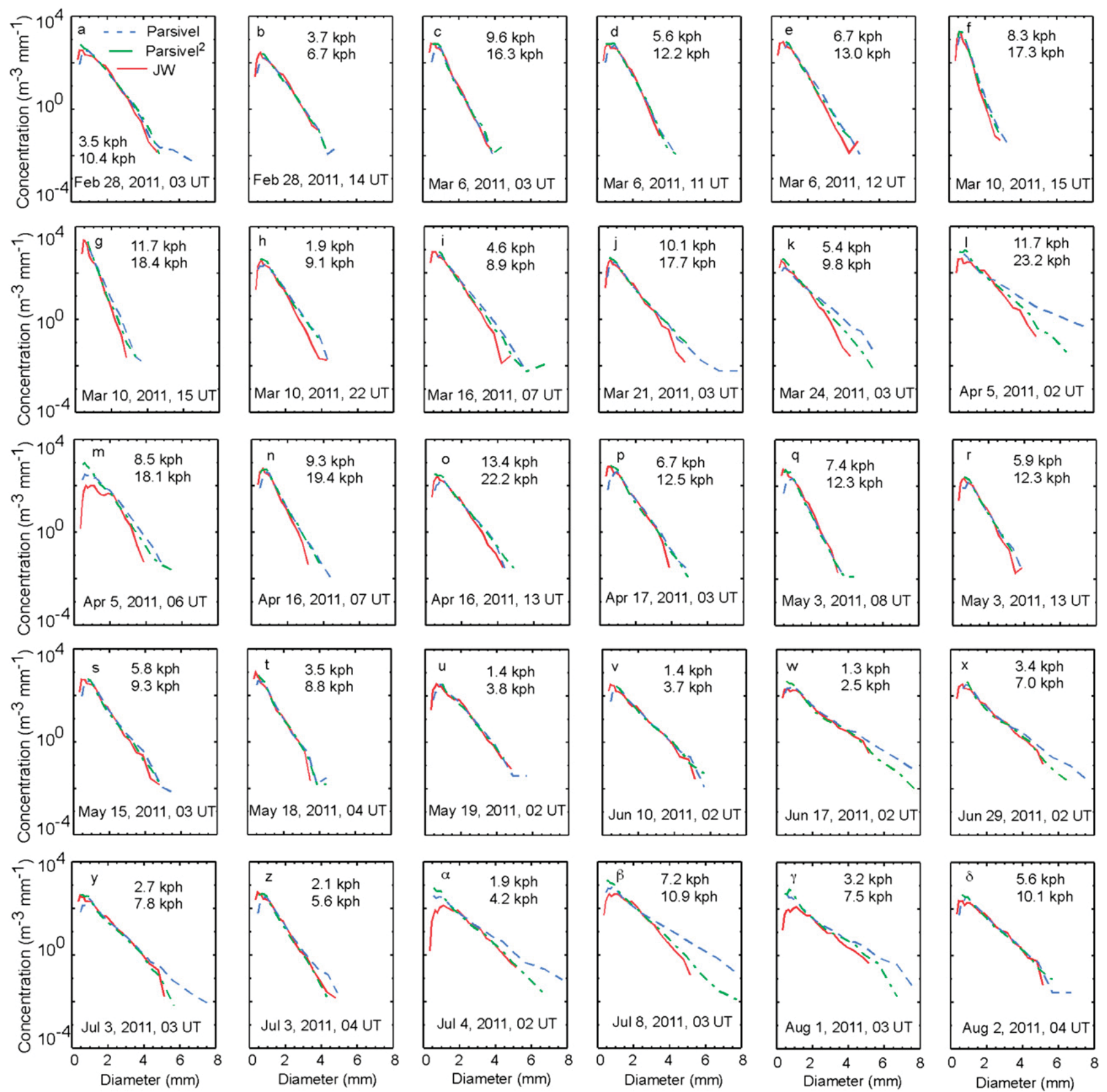

FIG. 4. Comparison of hourly raindrop spectra from 20 different rain events. The hourly spectrum is given for the JW disdrometer (solid), the OTT Parsivel disdrometer (dashed), and the OTT Parsivel ${ }^{2}$ disdrometer (dashed-dotted). The hourly mean and maximum wind speeds are also given $\left(\mathrm{km} \mathrm{h}^{-1}\right)$.

equal to $180 \mathrm{~mm} \times\left(30 \mathrm{~mm}-D_{i} / 2\right)$. The observational period, Time, is set to $60 \mathrm{~s}$ in this study. Although $v_{j}$ is the measured raindrop fall speed at the $j$ th velocity bin in Eq. (6), the terminal fall speed $v\left(D_{i}\right)$ is used in this study to eliminate any instrument-measured fall speed artifacts on the DSD, and therefore it provides a more direct comparison with JW-derived DSD. To avoid sampling fluctuations, we make sure that all composite DSDs have more than 10 rainy minutes in an hour and that the differences in the disdrometer's rainy minutes are less than $15 \%$. Figure 4 shows 30 one-hourly DSD composites for the JW, P1, and P2 for 20 rain events.

One shortcoming of the P1 is the underestimation of small drops with a sharp drop-off occurring toward smaller sizes after peak concentrations at 0.84 or $0.96 \mathrm{~mm}$ in diameter (TPGW13). In this study, P1 had peak concentrations at the same drop diameters except for a few rainy hours where the peak concentration 
occurred at a diameter of $0.58 \mathrm{~mm}$. The sharp drop-off toward smaller sizes was mostly observed in P1 hourly composites. The $\mathrm{P} 2$ exhibited peak concentrations mostly between 0.32 and $0.58 \mathrm{~mm}$, with no sharp decrease toward the smaller sizes. The JW disdrometer, on the other hand, had peak concentrations mostly from 0.44 to $0.65 \mathrm{~mm}$ but showed drastic drop-offs toward small sizes in a few cases (Figs. $4 \mathrm{~m} ; \alpha, \beta, \gamma$ ).

For midsize drops, the P2 and JW exhibited good agreement, while the $\mathrm{P} 1$ indicated higher concentrations of drops larger than 2.44 (Fig. 4; $\alpha$ ) and $2.82 \mathrm{~mm}$ (Fig. 4; $\beta$ ). The overestimation of mid- to large-size drops has been previously reported as another shortcoming of P1 (TPGW13). The P2 also exhibited higher concentrations of larger drops than the JW in a number of hourly composites (Figs. 4k,1; $\gamma$ ), but the differences in concentration were relatively less between the JW and P2 compared to the JW and P1. Although we did not select any disdrometer as a reference, the good agreement between the JW and P2 hourly DSDs in a broad size range $(0.5-4 \mathrm{~mm})$ suggests that $\mathrm{P} 2$ is likely a better instrument in measuring the size spectra than $\mathrm{P} 1$.

For the size spectra at drop diameters larger than $4 \mathrm{~mm}$, the sampling is limited and, of course, the JW cannot distinguish drops larger than $5.3 \mathrm{~mm}$. This makes it difficult to evaluate the full performance of the P2. However, the slope of the P2 DSD often followed JW, while $\mathrm{P} 1$ measured distinctly higher concentrations at these sizes (Figs. $4 \mathrm{w}, \mathrm{x} ; \alpha, \beta$ ). It should be noted that for several hourly DSDs, all three disdrometers showed good agreement except at the lower end of the spectrum in a number of hourly DSDs (Figs. 4b-d,q,s-v). For hourly DSDs, where the differences were significant, there was no wind dependency as previously suggested in TPGW13.

\section{Fall velocity measurements}

Raindrop trajectories may deviate from the vertical in windy conditions, but it is expected that the raindrop mean fall speed should follow the terminal fall velocity quite closely. At least the mean fall speed should not systematically deviate from the terminal fall velocity for all rain events. Figure 5 shows the mean and standard deviation of $\mathrm{P} 1$ and $\mathrm{P} 2$ fall velocities for 12 rain events, which recorded at least $10 \mathrm{~mm}$ of rainfall. The terminal fall velocity is also depicted as a reference.

There were significant differences in fall velocity measurements between the two disdrometers. P1 overestimated the fall velocities of small drops, where the difference between the mean measured and terminal fall velocity peaked at the smallest measurable size $(0.32 \mathrm{~mm})$ and the difference from terminal fall velocity was as high as $42 \%$ (Fig. 5a). The overestimation diminished with increasing size and mean fall velocities were less than terminal fall velocities, where the crossover occurred between 0.95 (Fig. 5k) and $1.67 \mathrm{~mm}$ (Fig. $5 \mathrm{~g})$. The difference between the mean measured and terminal fall velocity was as high as $18 \%$, which occurred at $1.67 \mathrm{~mm}$ (Fig. 5k). This was also a fairly windy event, with a maximum wind speed of approximately $32 \mathrm{~km} \mathrm{~h}^{-1}$. In a number of events, $\mathrm{P} 1$ overestimated the fall velocity of large drops at sizes $3.35 \mathrm{~mm}$ or larger (Fig. $5 \mathrm{w}$ ). The difference between the mean measured and terminal fall velocity was as high as $32 \%$, which was occurred at $6.69 \mathrm{~mm}$ (Fig. 5w).

The P2 mean fall velocities followed the terminal fall speed at smaller drop diameters up to $1.09 \mathrm{~mm}$, where differences between measured and terminal fall speeds remained less than $15 \%$. At diameters of $1.09 \mathrm{~mm}$, the P2 underestimated the fall speeds by $12 \%$ (Fig. 5j) and $27 \%$ (Fig. 5n). The manufacturer recognized this shortcoming as a software bug and is currently investigating the issue (K. Nemeth, OTT, 2013, personal communication). Underestimation of fall velocities was also evident for larger drops, but the difference between the measured and terminal fall speeds was not as pronounced. In a number of events, P2 overestimated the fall velocity of the drops at sizes larger than $3.35 \mathrm{~mm}$.

Fall velocity measurements play an important role in calculating the DSD, as shown in Eq. (6), as well as in rain parameters, except in rain rate. Figure 6 shows the 6-hourly P2 DSD from six different events where the DSD was calculated from both measured and terminal fall speeds. Visually, the differences between the measured and terminal fall speed DSDs do not appear significant; however, a closer look at the $1.09-\mathrm{mm}$ bin revealed that concentrations were $23 \%$ lower when the terminal fall speeds were used. This is consistent with approximately $1 \mathrm{~m} \mathrm{~s}^{-1}$ differences between the mean measured and terminal fall speeds.

Table 1 presents statistics that quantify the role of fall speed in total concentration, $N_{T}$; liquid water content, $W$; reflectivity; and mean $D_{\text {mass }}$. The statistics are based on $8685 \mathrm{P} 2$ observations, each of $1 \mathrm{~min}$, from the 36 rain events mentioned previously. The underestimation of fall velocities in the midsize drop-diameter bins dominated the DSD and rain parameters, resulting in a negative percent bias, since these parameters were calculated using terminal fall speed first. As in Eq. (6), the fall speed is in the denominator in calculating the DSD and integral rain parameters and, therefore, the underestimation of measured fall speeds results in higher DSD and rain parameters. The percent absolute biases for $N_{T}$ and $W$ were $8 \%$ and $13 \%$, respectively, while $Z$ had a $0.6-\mathrm{dB}$ absolute bias. The mean mass diameter $D_{\text {mass }}$, the ratio 

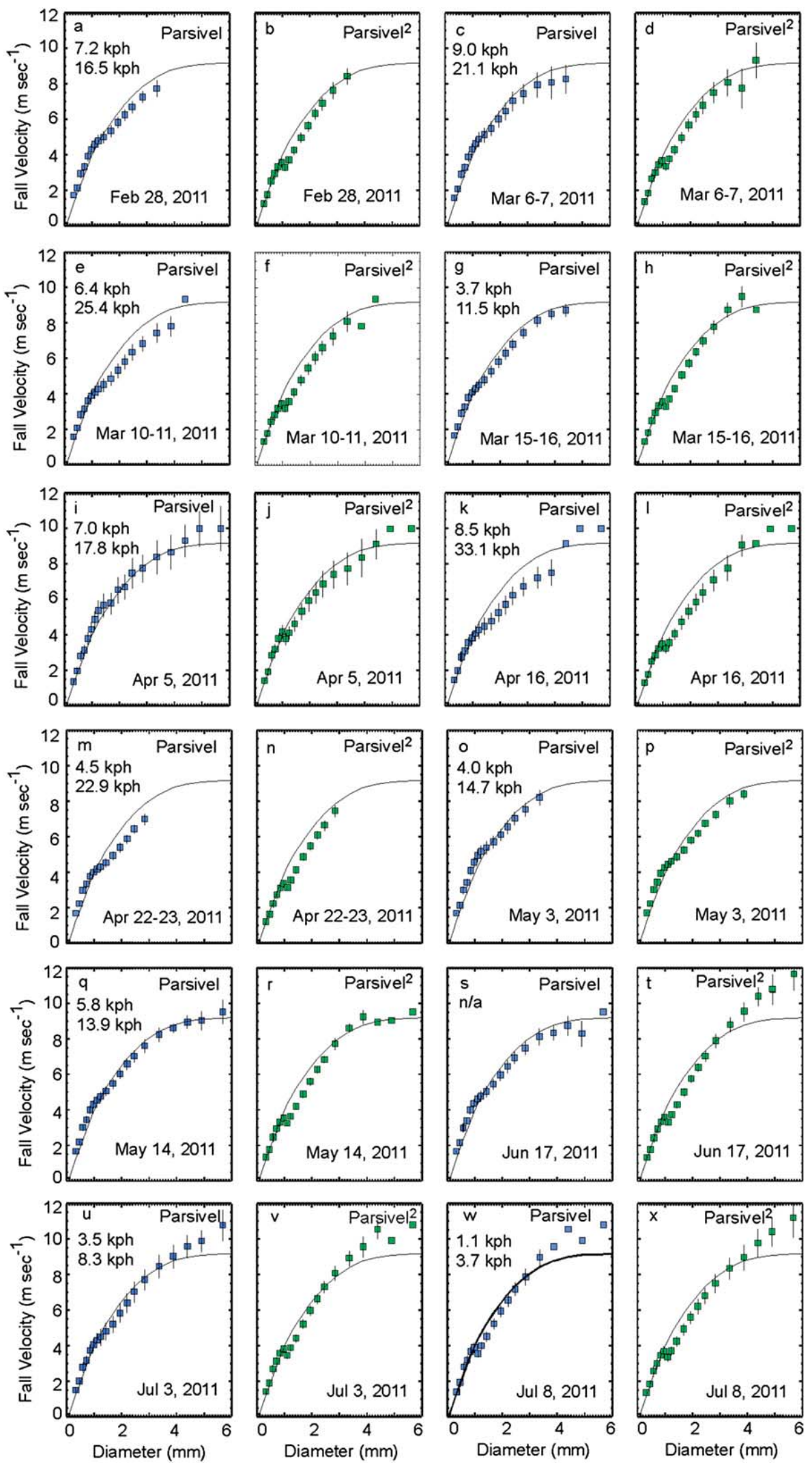

FIG. 5. Mean (squares) and standard deviation (vertical bars) of measured fall velocity by the OTT Parsivel and the Parsivel ${ }^{2}$ disdrometers as a function of diameter for 12 rain events. The terminal fall speed following Beard (1976) is shown as a solid line. The event mean and maximum wind speeds are also given $\left(\mathrm{km} \mathrm{h}^{-1}\right)$. 

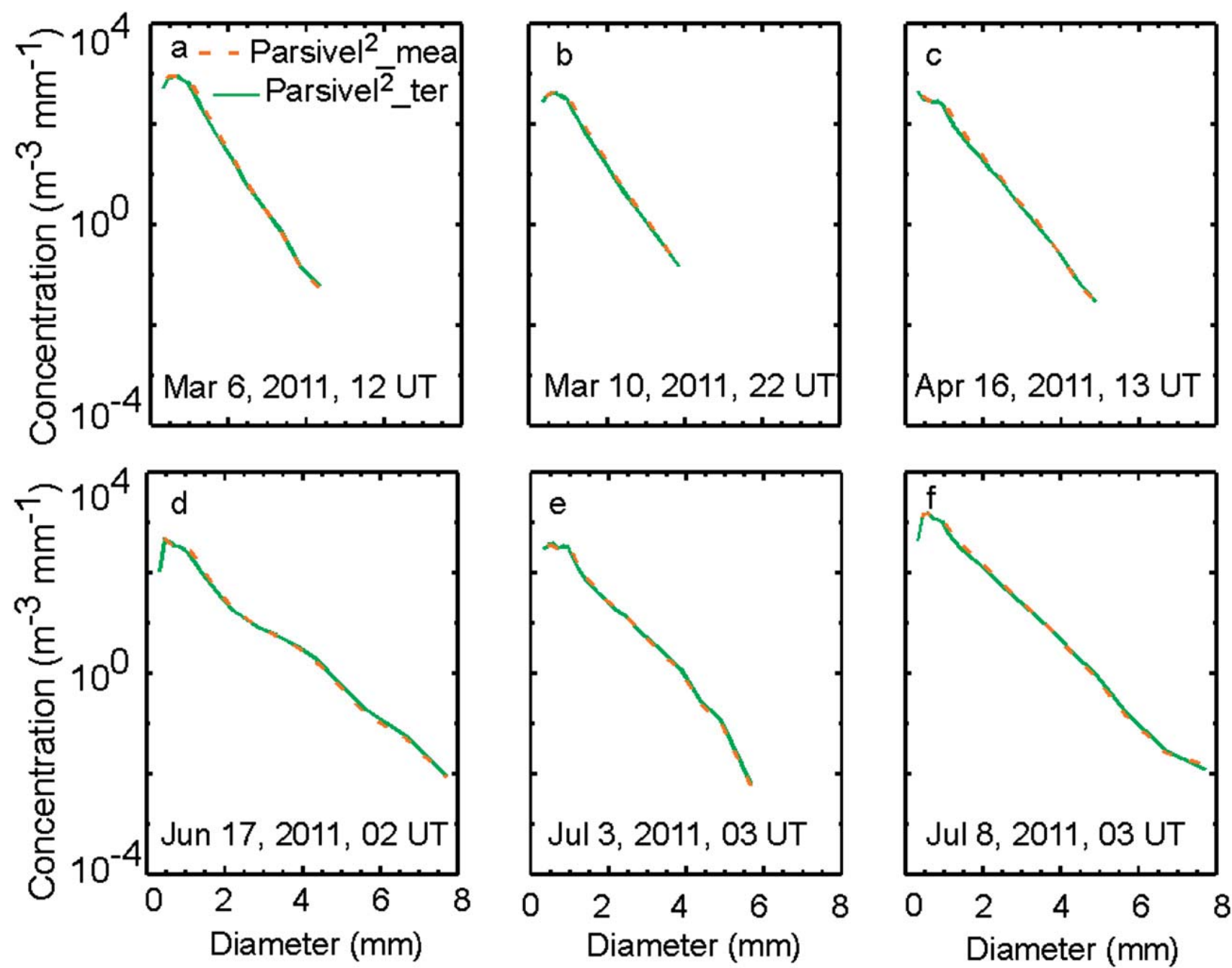

FIG. 6. Hourly OTT Parsivel ${ }^{2}$ raindrop size distributions from six different events. Hourly size distributions are calculated using measured (dashed) and terminal (solid) fall speeds.

of the fourth to the third moment of the DSD, exhibited a relatively insignificant bias of $0.02 \mathrm{~mm}$.

\section{Raindrop size distribution and integral rainfall parameters}

Probability and cumulative distributions of DSD and integral rain parameters were calculated from 8459 observations, each of $1 \mathrm{~min}$, for which all three disdrometers reported rainfall. To be consistent with the JW disdrometer, the terminal fall speed was used in calculating DSD and rainfall parameters from the Parsivel disdrometers. The DSD is formulated by a three-parameter normalized gamma function (Tokay and Bashor 2010) and is given as

$N(D)=N_{T}^{*} f_{1}(m)\left(\frac{D}{D_{\text {mass }}}\right)^{m} \exp \left[-(4+m) \frac{D}{D_{\text {mass }}}\right]$ and
$N(D)=N_{w} f_{2}(m)\left(\frac{D}{D_{\text {mass }}}\right)^{m} \exp \left[-(4+m) \frac{D}{D_{\text {mass }}}\right]$

where $N_{T}^{*}$ and $N_{W}$ are the normalized intercept parameters with respect to $N_{T}$ and $W$, respectively; and $m$ is the shape parameter. The terms $f 1$ and $f 2$

TABLE 1. Rainfall statistics of raindrop size distribution $\left(D_{\text {mass }}\right)$ and integral rain $\left(N_{T}, W, Z\right)$ parameters that are calculated from OTT Parsivel ${ }^{2}$ measured and terminal fall speeds. Bias and percent bias are calculated using terminal fall speed first.

\begin{tabular}{llccc}
\hline \hline & Bias & ab_bias & per_bias $(\%)$ & per_ab_bias $(\%)$ \\
\hline$N_{T}\left(\mathrm{~m}^{-3}\right)$ & -26 & 35 & -6 & 8 \\
$W\left(\mathrm{~g} \mathrm{~m}^{-3}\right)$ & -0.017 & 0.625 & -13 & 13 \\
$Z(\mathrm{~dB})$ & -0.6 & 0.6 & -1 & 2 \\
$D_{\text {mass }}(\mathrm{mm})$ & -0.01 & 0.02 & -1 & 2
\end{tabular}


are the function of the shape parameter and are expressed as

$$
\begin{aligned}
& f_{1}(m)=\frac{(4+m)^{m+1}}{\Gamma(m+1)} \text { and } \\
& f_{2}(m)=\frac{6}{256} \frac{(4+m)^{m+4}}{\Gamma(m+4)},
\end{aligned}
$$

respectively. Both normalized intercept parameters and $D_{\text {mass }}$ were directly calculated from disdrometer measurements, while the shape parameters were obtained by minimizing the error between the observed and gammafitted DSD-based rain rates. The complete gamma function was assumed in calculating the rain rate from the gamma-fitted DSD. The range of the shape parameter was considered to be between -2 and 20 , even though higher values were occasionally reported (Tokay and Short 1996). Approximately $12 \%$ of the data were disregarded because they were outside this range. Outof-range values for the shape parameters are partly due to the use of complete gamma functions and partly because the gamma fit was not well suited to the observed DSD spectra.

Probability and cumulative distributions of integral parameters $(R, W, Z)$ and $D_{\text {mass }}$ showed good agreement between the three disdrometers (Figs. 7a-h), but there were noticeable differences in mean values of these parameters between the instruments (Table 2). This is the result of the differences in the disdrometer DSDs, where a particular size regime contributes the most to a particular rain parameter. The contributions of small, midsize, and large drops differed from each other for $R$, $W$, and $Z$ at different rain intensities. The $\mathrm{P} 2$ had higher mean rain rates than JW and lower mean rain rates than P1. For the liquid water content, both Parsivels had similar means, which were higher than the JW mean value. P2 had 1 and $3.4 \mathrm{~dB}$ lower mean reflectivity than the JW and P1 mean reflectivity, respectively. The underestimation of small to midsize drops resulted in lower mean $W$ and $R$ in JW disdrometers (Figs. $4 \mathrm{~m} ; \alpha, \gamma$ ) and the overestimation of midsize to large drops resulted in higher $R$ and $Z$ in $\mathrm{P} 1$ (Figs. 4k; $\alpha, \beta$ ).

Probability and cumulative distributions of intercept and shape parameters of the gamma DSD showed good agreement between JW and P2, but the distributions were shifted toward lower intercept and higher shape parameters in P1 (Figs. 7i-p). P2 had the highest mean intercept parameter, while the $\mathrm{P} 1$ had the lowest. This was due to the underestimation of small drops in the JW and P1, where the latter exhibited a sharp drop off at small sizes (Figs. 4j,m,o,w). The mean shape parameters of the P2 were 5.6 and 5.3 for fitted gamma DSDs based on Eqs. (6) and (7), respectively, in a good agreement with the mean shape parameter of the JW.

The distribution of the triplet of gamma DSD parameters plays an important role in the formulation of the spaceborne radar rainfall retrieval algorithms. NASA's Tropical Rainfall Measuring Mission (TRMM) precipitation radar rainfall algorithm employs a gamma DSD with fixed shape parameter $(m=3)$ (Kozu et al. 2009), also indicated in the probability distributions in Figs. 7k,1. NASA's Global Precipitation Measurement (GPM) mission precipitation radar rainfall algorithm, on the other hand, will also use the gamma-based DSD, and an empirical relationship between the parameters of gamma DSD, such that it can retrieve all parameters of DSD from its dual-frequency measurements, is highly desirable (R. Meneghini, NASA Goddard Space Flight Center, 2013, personal communication).

\section{Conclusions}

Affordability, easy installation and maintenance, and robustness of hardware in the field have resulted in worldwide use of the Parsivel disdrometer in many applications of Earth sciences and beyond. However, there have been relatively few independent studies that have evaluated the performance of the OTT Parsivel through field studies. As noted in TPGW13, P1 underestimated the concentrations of small drops less than $0.76 \mathrm{~mm}$ and overestimated the drop concentration for drop diameters larger than $2.4 \mathrm{~mm}$, particularly in heavy rain. The fall velocity measurements made using P1 seem to be better than the PM Tech version, as the mean fall speeds measured by the former followed well-established empirically derived terminal fall speed relationships more closely.

Herein, we compared a collocated newer version of the OTT Parsivel (Parsivel ${ }^{2}$ ) to its predecessor, a JW disdrometer, and a collocated rain gauge pair. The OTT Parsivel $^{2}$ showed better agreement with the reference rain gauge than the Parsivel and JW disdrometers. Good agreement was also evident in hourly DSDs between JW and Parsivel $^{2}$, with drop diameters in the range of 0.5$4 \mathrm{~mm}$. Parsivel ${ }^{2}$ drop concentrations generally increased toward smaller size bins, peaking in the first three measurable size bins of $0.34-0.58 \mathrm{~mm}$. These features demonstrated that the Parsivel $^{2}$ is indeed an improved version of the OTT Parsivel for the raindrop size and rainfall measurements. The Parsivel ${ }^{2}$-measured raindrop fall velocities approximately followed the expected terminal fall speeds at the small end of the drop spectrum, but there was approximately $1 \mathrm{~m} \mathrm{~s}^{-1}$ difference between the mean measured and terminal fall speeds at $1.09 \mathrm{~mm}$. This discrepancy may exert a pronounced 

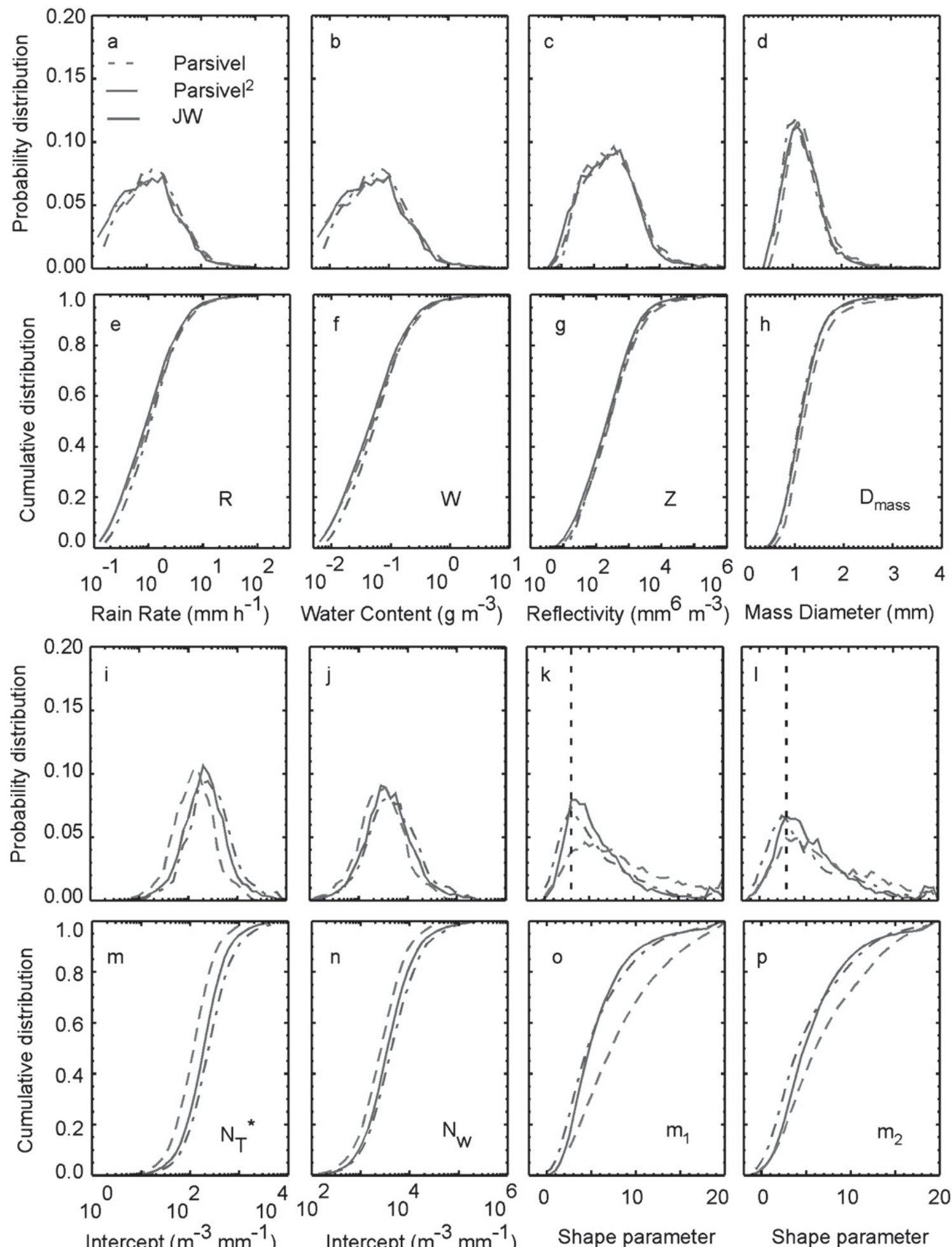

FIG. 7. Probablity and cumulative distributions of (a),(e) rain rate; (b),(f) liquid water content; (c),(g) reflectivity; (d),(h) mean mass diameter; (i),(m) intercept of gamma-fitted distribution with respect to $N_{T}$ and $D_{\text {mass }}$; (j),(n) intercept of gamma-fitted distribution with respect to $W$ and $D_{\text {mass }} ;(\mathrm{k})$,(o) shape parameter of gamma-fitted distribution with respect to $N_{T}^{*}$; and (1),(p) shape parameter of gamma-fitted distribution with respect to $N_{w}$ from JW (solid), OTT Parsivel (dashed), and OTT Parsivel ${ }^{2}$ (dashed-dotted) disdrometers. The shape parameter of 3 , which is used for the TRMM precipitation radar algorithm, is marked as a vertical dash line in (k) and (l). 
TABLE 2. Rainfall statistics of raindrop size distribution $\left(D_{\text {mass }}, N_{T}^{*}, N_{W}, m_{1}, m_{2}\right)$ and integral rain $(R, W, Z)$ parameters. The terms $m_{1}$ and $m_{2}$ refer to the shape parameters of the gamma distribution with respect to $N_{T}^{*}$ and $N_{W}$.

\begin{tabular}{lccc}
\hline \hline & mean; std dev $(\mathrm{JW})$ & mean; std dev (Parsivel) & mean; std dev $\left(\right.$ Parsivel $\left.^{2}\right)$ \\
\hline$R\left(\mathrm{~mm} \mathrm{~h}^{-1}\right)$ & $2.2 ; 5.2$ & $2.9 ; 9.3$ & $2.5 ; 6.1$ \\
$W\left(\mathrm{~g} \mathrm{~m}^{-3}\right)$ & $0.120 ; 0.210$ & $0.139 ; 0.340$ & $0.140 ; 0.255$ \\
$Z(\mathrm{~dB})$ & $35.7 ; 40.0$ & $38.1 ; 47.9$ & $34.7 ; 42.7$ \\
$D_{\text {mass }}(\mathrm{mm})$ & $1.16 ; 0.42$ & $1.28 ; 0.51$ & $1.16 ; 0.45$ \\
$N_{T}^{*}\left(\mathrm{~m}^{-3} \mathrm{~mm}^{-1}\right)$ & $332 ; 535$ & $180 ; 211$ & $465 ; 791$ \\
$N_{W}\left(\mathrm{~m}^{-3} \mathrm{~mm}^{-1}\right)$ & $8317 ; 18486$ & $4637 ; 6444$ & $10088 ; 19337$ \\
$m_{1}$ & $5.7 ; 3.8$ & $8.1 ; 4.9$ & $5.6 ; 4.2$ \\
$m_{2}$ & $5.7 ; 4.3$ & $7.1 ; 4.9$ & $5.3 ; 4.5$ \\
\hline
\end{tabular}

effect on computed DSD and integral rainfall parameters. Though the manufacturer will eventually correct the fall velocity issue in its software, the impact of the error can be mitigated for rain, as it is feasible to use terminal fall speed in calculating DSD and rainfall parameters with modest error. However, the fall speed error may not be as easy to mitigate in snow, since the flake size versus terminal fall speed relation depends on habit and environmental conditions. The NASA GPM Cold-Season Precipitation Experiment in southern Ontario, Canada, and the World Meteorological Organization lead the Solid Precipitation Intercomparison Experiment in Finland and Canada will provide an excellent opportunity to evaluate the performance of the Parsivel $^{2}$ in snow.

As reported in LJ00 study, the Parsivel could estimate the size of drizzle drops down to $0.1 \mathrm{~mm}$ in diameter with a modification in the optical system. This will provide a better estimate of total concentration and improve DSD parameterization. The raw output could be the specific information for each drop, including its time stamp, size, and fall velocity, rather than 32 size $\times 32$ fall velocity matrix. The problematic issue of fall velocity measurements at $1 \mathrm{~mm}$ and larger sizes is expected to be resolved through a software update. This study is limited to rainfall, and similar comparative studies between the collocated disdrometers are needed to evaluate the performance of the OTT Parsivel ${ }^{2}$ in snow. It should be pointed out that communications between the manufacturer and the users is key for diagnosing and correcting any issues of the instrument as well as for planning the next generation.

Acknowledgments. Many thanks to David A. Makofski and Jianxin (Jerry) Wang of Science Systems and Applications, Inc., for the installation and data collection of the disdrometers and rain gauges. Feedback from manufacturer of the OTT Parsivel is greatly appreciated. This study was funded under NASA's Global Precipitation Measurement mission under Arthur
Hou of NASA's Goddard Space Flight Center, project scientist, and Precipitation Measurement Mission (PMM) Grants NNX07AF45G and NNX10AJ12G under Ramesh Kakar of NASA headquarters, program scientist. Acknowledgments extend to Mathew Schwaller of NASA's Goddard Space Flight Center, GPM Ground Validation project manager, for his continuous support.

\section{REFERENCES}

Battaglia, A., E. Rustemeier, A. Tokay, C. Simmer, and U. Blahak, 2010: PARSIVEL snow observations: A critical assessment. J. Atmos. Oceanic Technol., 27, 333-344, doi:10.1175/ 2009JTECHA1332.1.

Beard, K. V., 1976: Terminal velocity and shape of cloud and precipitation drops aloft. J. Atmos. Sci., 33, 851-864, doi:10.1175/1520-0469(1976)033<0851:TVASOC >2.0.CO;2.

Hauser, D., P. Amayenc, B. Nutten, and P. Waldteufel, 1984: A new optical instrument for simultaneous measurement of raindrop diameter and fall speed distributions. J. Atmos. Oceanic Technol., 1, 256-269, doi:10.1175/1520-0426(1984)001<0256: ANOIFS $>2.0 . \mathrm{CO} ; 2$

Joss, J., and A. Waldvogel, 1967: Ein spectrograph für Niederschlasgstropfen mit automatischer Auswertung (A spectrograph for the automatic analysis of raindrops). Pure Appl. Geophys., 68, 240-246, doi:10.1007/BF00874898.

Kozu, T., T. Iguchi, T. Shimomai, and N. Kashiwagi, 2009: Raindrop size distribution modeling from a statistical rain parameter relation and its application to the TRMM precipitation radar rain retrieval algorithm. J. Appl. Meteor. Climatol., 48, 716-724, doi:10.1175/2008JAMC1998.1.

Krajewski, W. F., and Coauthors, 2006: DEVEX-Disdrometer Evaluation Experiment: Basic results and implications for hydrologic studies. Adv. Water Resour., 29, 311-325, doi:10.1016/ j.advwatres.2005.03.018.

Kruger, A., and W. F. Krajewski, 2002: Two-dimensional video disdrometer: A description. J. Atmos. Oceanic Technol., 19, 602-617, doi:10.1175/1520-0426(2002)019<0602:TDVDAD>2.0.CO;2.

Lanza, L. G., and E. Vuerich, 2009: The WMO field intercomparison of rain intensity gauges. Atmos. Res., 94, 534-543, doi:10.1016/j.atmosres.2009.06.012.

Löffler-Mang, M., and J. Joss, 2000: An optical disdrometer for measuring size and velocity of hydrometeors. J. Atmos. Oceanic Technol., 17, 130-139, doi:10.1175/1520-0426(2000)017<0130: AODFMS $>2.0 . \mathrm{CO} ; 2$. 
Schönhuber, M., G. Lammer, and W. L. Randeu, 2007: One decade of imaging precipitation measurement by $2 \mathrm{D}$-video-disdrometer. Adv. Geosci., 10, 85-90, doi:10.5194/adgeo-10-85-2007.

Sevruk, B., 1996: Adjustment of tipping-bucket precipitation gauge measurements. Atmos. Res., 42, 237-246, doi:10.1016/ 0169-8095(95)00066-6.

Thurai, M., W. A. Petersen, A. Tokay, C. Schultz, and P. Gatlin, 2011: Drop size distribution comparisons between Parsivel and 2-D video disdrometers. Adv. Geosci., 30, 3-9, doi:10.5194/adgeo-30-3-2011.

Tokay, A., and D. A. Short, 1996: Evidence from tropical raindrop spectra of the origin of rain from stratiform versus convective clouds. J. Appl. Meteor., 35, 355-371, doi:10.1175/ 1520-0450(1996)035<0355:EFTRSO > 2.0.CO;2.

_ , and P. G. Bashor, 2010: An experimental study of small-scale variability of raindrop size distribution. J. Appl. Meteor. Climatol., 49, 2348-2365, doi:10.1175/2010JAMC2269.1.
- — - and K. R. Wolff, 2005: Error characteristics of rainfall measurements by collocated Joss-Waldvogel disdrometers. J. Atmos. Oceanic Technol., 22, 513-527, doi:10.1175/ JTECH1734.1.

— W. W. Aetersen, P. Gatlin, and M. Wingo, 2013: Comparison of raindrop size distribution measurements by collocated disdrometers. J. Atmos. Oceanic Technol., 30, 1672-1690, doi:10.1175/JTECH-D-12-00163.1.

Vuerich, E., C. Monesi, L. G. Lanza, L. Stagi, E. Lanzinger, 2009: WMO field intercomparison of rainfall intensity gauges. World Meteorological Organization Instruments and Observing Methods Rep. 99, WMO/TD-1504, 290 pp.

Yuter, S. E., D. E. Kingsmill, L. B. Nance, and M. Löffler-Mang, 2006: Observations of precipitation size and fall velocity characteristics within coexisting rain and wet snow. J. Appl. Meteor. Climatol., 45, 1450-1464, doi:10.1175/JAM2406.1. 